\title{
JOGO EDUCATIVO PARA ENSINO E APRENDIZAGEM DA LINGUAGEM DE LIBRAS: UMA ABORDAGEM DO DESIGN SOCIAL
}

\author{
PEIXE, Rita Inês Petrykowski; Msc; Universidade da Região de Joinville - \\ UNIVILLE; ritapeixe@ hotmail.com \\ ANSELMO, Juliana Silveira; Msc; Universidade da Região de Joinville - \\ UNIVILLE; juliana.anselmo@univille.net \\ MEDEIROS, Ivan Luiz de; Especialista; Universidade da Região de Joinville - \\ UNIVILLE; ivan.medeiros@univille.br \\ OLIVEIRA, Sônia Teresinha Serpa de; Especialista; Universidade da Região de \\ Joinville - UNIVILLE; ed_especial@ hotmail.com
}

\begin{abstract}
Resumo
O presente artigo é parte de uma pesquisa experimental que propõe estudos e inferências com vistas ao desenvolvimento de material lúdico-educativo, cujo intuito será contribuir para a promoção do ensino e aprendizagem da linguagem de Libras. Tais materiais têm como foco de interesse propiciar a interação mais efetiva de crianças surdas e ouvintes em ambientes de aprendizagem, sendo de extrema importância para o desenvolvimento da identidade cultural e processos inclusivos, em especial daquelas em fase escolar que apresentam deficiência auditiva. Aliada à proposição de unir técnicas de design a processos de ensino e aprendizagem através de conteúdos lúdicos, o projeto de pesquisa tem como meta a construção de um Jogo de Tabuleiro que incentiva o diálogo e a interação entre crianças surdas e ouvintes em situações diversas, ao mesmo tempo em que aborda alguns assuntos que podem ser explorados em disciplinas escolares antes e após a brincadeira. Verificou-se, a partir das informações apreendidas durante a pesquisa, que existem outras inúmeras possibilidades de criação de jogos ou materiais lúdico-educativos, principalmente no que tange à investigação e sua aplicação no estímulo ao desenvolvimento da cultura visual do surdo.
\end{abstract}

Palavras-chave: Design Social, Desenvolvimento de Produto, Linguagem de Libras.

\section{EDUCATIONAL GAME TO LEARNING TEACH AND SIGN LANGUAGE: AN APPROACH TO SOCIAL DESIGN}

\begin{abstract}
This article is part of an experimental research which proposes studies and interferences with the goal of the development of educational material to learning teach and sign language. Such materials have focused interest on providing a more effective interaction of deaf and hearing children in learning environments. Such materials focus on allowing more effective interaction between normal children and those with hearing disabilities in learning environments, being extremely important to cultural identity development and inclusive processes, specially to those that show that kind of disability during school period. Merging design techniques with teaching and learning processes, this research have as an objective the creation of a board game that stimulate dialogue and interaction between normal children and those with hearing disabilities in several
\end{abstract}


situations,, at the same time exploring subjects that may be approached on school classes, before and after the playing. It was observed that, using information collected during rthis research, that there are several game or ludic and educational material creation possibilities, specially regarding investigation and application on stimulating visual culture development on people with hearing disabilities.

Keywords: Social Design, Product Development, Sign Language.

\section{INTRODUÇÃO}

O Brasil recebeu grande influência de tendências pedagógicas estrangeiras durante o processo de desenvolvimento da educação dos surdos. Estas, por sua vez, seguiam os moldes da educação de ouvintes, ou seja, a imposição da oralidade, deixando de lado a identidade cultural dos alunos surdos. Porém, todos precisam interagir em seu meio, tomar conhecimento de sua cultura, sua história e, através do convívio e interação com o outro, formar sua identidade (CAPORALI e DIZEU, 2005).

Para a pessoa com deficiência auditiva, as relações com o meio são de igual importância, para que ela possa construir sua identidade e sua visão do mundo. A grande mediadora dessas interações e significações é a linguagem, apresentando-se assim a importância de sua aquisição, uma vez que, para os ouvintes, é a Língua Portuguesa e, para o surdo, é a Língua Brasileira de Sinais - Libras (GESUELI, 2004; QUADROS, 2006).

Visto que, surdos e ouvintes não compartilham da mesma linguagem, utilizando idiomas diferentes, surgem inúmeras dificuldades para que ocorra o necessário diálogo entre as partes. É comum que em uma sala de aula, as crianças surdas tenham dificuldade na escrita e leitura em português, e as ouvintes desconheçam a linguagem de Libras, não desconsiderando que alguns surdos também não possuem o domínio da linguagem de Libras. Uma das alternativas para promover a comunicação e expressão em sala de aula, pode ser a utilização de atividades com conteúdos lúdicos. Por meio de jogos é possível abrir uma porta para o mundo social e para a cultura infantil, encontrando, desta maneira, uma rica possibilidade de incentivar o seu desenvolvimento, trazendo mais prazer e novas perspectivas à vida das crianças (FRIEDMANN, 1996).

Entende-se que é no contexto escolar que o surdo encontra a possibilidade de construir seu espaço, através do convívio com outros surdos e professores especializados, já que grande parte surdos são filhos de pais ouvintes (PAULA, 2005).

Conforme a Política de Educação de Surdos de Santa Catarina (2004) as questões da construção da identidade do surdo envolvem o reconhecimento do modo de vida, visão de mundo e situações sociolingüísticas específicas vividas por esta comunidade. Trabalhar com tais diferenças significa compreender o surdo como uma pessoa que possui um idioma diferente, uma língua materna que não é a linguagem corrente; significa conhecer a sua forma de comunicação, usá-la e oportunizar a ele, surdo, a aquisição de conhecimentos nas duas línguas (primeiro na sua - de sinais - e depois na língua portuguesa) de forma sistemática, continuada, dialógica, para que, verdadeiramente, ele possa construir sua identidade e exercer o direito da cidadania.

Neste contexto e sob tal foco de importância, foi proposto em 2010 o Projeto de Pesquisa DLIBRA, que partiu de estudos e inferências, com o intuito inicial de propor o desenvolvimento de materiais lúdico-educativos para ensino e aprendizagem da 
linguagem de Libras, promovendo, assim, a interação em ambiente escolar entre crianças surdas e ouvintes.

O projeto teve como apoiador, em seu primeiro ano de atividades, a Escola de Ensino Fundamental Rui Barbosa, Instituição pólo no ensino bilíngüe na região de Joinville, constando que, no total, são três escolas da Rede Pública Estadual de educação bilíngüe em todo o Estado de Santa Catarina.

\section{REVISÃO DE LITERATURA Interação entre surdos e ouvintes}

Quando a sociedade ouvinte marginaliza a pessoa com deficiência auditiva e a desrespeita como cidadão com deveres e direitos diante do espaço social, cria-se um estigma de incapacidade que não leva o ser humano a se desenvolver plenamente. Revertendo esta situação, permitindo que o surdo possa ter contato com seus pares, conhecer sua cultura, usar a língua que é própria da sua condição - a Libras, ele terá consciência do significado de sua cultura e percepção de si próprio (DIZEU E CAPORALI, 2005).

De acordo com Souza (1998), a partir do momento em que os surdos passaram a se reunir em escolas, associações e a se constituírem em grupo por meio de uma língua, passaram a ter a possibilidade de refletir sobre um universo de discursos acerca deles próprios e com isso conquistaram um espaço favorável para o desenvolvimento ideológico da própria identidade. Há, com isso, uma significativa mudança no modo de vida dessas comunidades surdas, considerando a sua proposta de comunicação.

Segundo Lodi (2005), no caso dos surdos, apenas a língua de sinais pode possibilitar tal mudança. É, portanto, por seu intermédio, que os surdos podem ter acesso à linguagem escrita por meio de práticas sociais nas quais os sinais gráficos são utilizados em sua dimensão discursiva, propiciando relações dialógicas. Através dessa comunicação, os surdos podem dialogar com a escrita, fazer suas próprias leituras, construir seus sentidos, "falar" sobre os materiais escritos, ao mesmo tempo em que são "falados" por eles. Tornam-se interlocutores a partir de suas próprias histórias (de mundo e como leitores).

Para promover a interação dos surdos com os ouvintes dentro da escola ou até mesmo no ambiente familiar propõe-se atividades lúdicas para tal finalidade. $\mathrm{O}$ brincar requer envolvimento emocional, contato social, ações físicas, além de relações cognitivas na expressão e apreensão das regras da brincadeira (LIMA, 1989).

Em grande parte, nas sociedades contemporâneas, a infância é marcada pelo brincar, que se processa através de práticas culturais típicas, mesmo que esteja muito reduzida face à demanda do trabalho infantil que ainda se insere no cotidiano dos segmentos sociais de baixa renda. A brincadeira permite à criança vivenciar o lúdico e descobrir-se a si mesma, apreender a realidade, tornando-se capaz de desenvolver seu potencial criativo (SIAULYS, 2005).

Valsiner (1988) destaca que a criança como ser ativo no processo de 'viver a brincadeira', vai além da cultura de seus pais e professores, uma vez que reconstrói as experiências adquiridas nos espaços familiares, escolares e comunitários. Ela cria, para suas brincadeiras, funções e cenários novos, tendo como referente as sugestões sociais, oferecidas por seu grupo. Portanto, externaliza sua subjetividade sobre os eventos sociais e, ao mesmo tempo, reconstrói o significado social da brincadeira.

Segundo Queiroz (2006), a brincadeira oferece às crianças uma ampla estrutura básica para mudanças das necessidades e tomada de consciência: ações na esfera 
imaginativa, criação das intenções voluntárias, formação de planos da vida real, motivações intrínsecas e oportunidade de interação com o outro, que, sem dúvida contribuirão para o seu desenvolvimento.

Os estudos de Brougère (2004) relatam que o jogo educativo surge como um complemento e um prolongamento da atividade escolar, possibilitando um reforço do ensino. Porém, o que caracteriza se esses jogos sejam considerados educativos não é tanto a motivação lúdica e sim os temas abordados por intermédios desses princípios. A possibilidade de trazer o jogo para dentro da escola é a oportunidade de pensar a educação numa perspectiva criadora, autônoma e consciente.

Por meio de jogos é possível abrir uma porta para o mundo social e para a cultura infantil, encontrando, desta maneira, uma rica possibilidade de incentivar o seu desenvolvimento, trazendo assim, mais prazer e ludicidade à vida das crianças (FRIEDMANN, 1996). Colaborando para tal ação, o design social vem com a proposta de atender a carência de materiais lúdico-educativos presente no mercado.

Ao apontar a natureza e o significado do jogo como fenômeno cultural, Huizinga (2008, p. 04) nos orienta que ele "transcende a necessidade imediata da vida e confere um sentido à ação [uma vez que tal sentido] implica a presença de um elemento não material em sua essência". Quadros (1997) conclui que a criança surda precisa criar sua própria teoria de mundo através de experiências diárias, interagindo de forma efetiva com indivíduos do seu meio. Isso significa que a escola deve ir além de seu trabalho profissional didático, promovendo programas que possibilitem essa inter-relação de crianças surdas e indivíduos ouvintes e compreendendo que os aspectos da visualidade são de grande importância quando se trata de alunos surdos.

\section{O Design Social}

Com o intuito de dar continuidade à pesquisa desenvolvida em 2010 e permitir uma ampliação de materiais lúdico-educativos que sirvam de subsídios para uma interação entre ouvintes e surdos, se faz necessário compreender melhor o contexto de projeto do design social. Fornasier (2005) explica que design social é a materialização de uma idéia por meio de análise, planejamento, execução e avaliação que resultam num conceito e na difusão de um conhecimento para influenciar o comportamento voluntário do público-alvo (beneficiários), promovendo mudanças sociais.

Em 1972 Vitor Papanek, desenhista industrial e diretor de Design do Instituto de Artes da Califórnia, publicou um livro que serviria como agenda para o design social, "Design for the real world". Com a publicação deste livro, Papanek abriu um novo nicho de mercado para designers, transformando o design não só em uma ferramenta para novidades no mercado, mas também procurando desenvolver programas de design para necessidades sociais, desde as necessidades de países em desenvolvimento até as necessidades específicas de idosos, pobres e portadores de deficiência (PADULA, 2003).

Segundo Amariliam (2000) não seria correto separar um "modelo de mercado" de um "modelo social" como se fossem distintos, mas sim como estudos paralelos. Vários produtos desenvolvidos para o mercado terminam por atender também a necessidades sociais, mas é fato que o mercado ainda não consegue abranger todas essas necessidades.

Segundo Resende (2004) o designer não projeta simplesmente bens ou serviços para empresas, ele pratica uma profissão que implica em ações determinadas pela ética e moral, com a tarefa de gerar a forma de um produto, considerando todas as condicionantes. Isto significa que o trabalho do designer não se encerra ao finalizar um 
produto, nem na entrega de um projeto, mas em um acompanhamento de toda a sua implantação no mercado e até mesmo de seu descarte.

O design social é uma forma diferenciada de pensar em design, que, em detrimento do foco em consumismo, auxilia no desenvolvimento de produtos que possam atender as mais diversas necessidades humanas. A abrangência dessa proposta pode ser melhor compreendida através da definição elaborada pelo FIDS (2009, p. 01),

[...] o Design Social é entendido como uma ferramenta de inovação e de comunicação, capaz de transformar necessidades e desejos humanos em produtos e sistemas de modo criativo e eficaz, adequados não somente do ponto de vista econômico, mas também, sociais, culturais e ecologicamente responsáveis.

Essa ferramenta de desenvolvimento se embasa na relação entre o usuário e o produto, observada através de relatórios e pesquisa com fundamento em seus anseios e necessidades primárias. Ao discutir sobre um "Modelo Social" de design, Margolin e Margolin (2004) afirmam que a observação participante é um método que possibilita o ingresso de designers em ambientes sociais, tanto como parte de um grupo multidisciplinar ou individualmente, para observar e documentar as necessidades sociais que podem ser atendidas com a intervenção do design.

\section{Estudos culturais e cultura visual}

Para a referida pesquisa, verificou-se a necessidade de explorar os conceitos da cultura visual, visto sua ampla abordagem e atuação nos meios de interação. "O universo do visual é, na atualidade, como sempre foi, mediador de valores culturais" (HERNÁNDEZ, 2000, p. 23) e é em torno e a partir dele que se constroem as identidades culturais, no sentido de um melhor conhecimento de si mesmo e do mundo.

Da Antropologia Cultural, cujo conceito encontra-se no centro dos estudos culturais, parte o reconhecimento de que:

(...) todos os seres humanos vivem num mundo criado por eles mesmos, e onde encontram significado. A cultura começa no ponto em que os humanos superam o que quer que seja dado em sua herança natural. O cultivo do mundo natural, na agricultura e na horticultura, é então um elemento fundamental de uma cultura. Desta forma, os dois elementos mais importantes ou gerais da cultura podem ser a habilidade dos seres humanos para construir e a habilidade para usar a linguagem (compreendida mais amplamente, para englobar todas as formas de sistema de signos) (EDGAR \& SEDGWICK, 2003, p. 75).

Como um "legado comum da humanidade" (SANTOS, 1988, p. 86), a cultura, e no seu âmbito das produções artísticas, registra e responde às tendências históricas e suas transformações no seio da sociedade. Assim, mais sentidos podem ser compartilhados a partir dessa acepção, compreendendo cultura como sendo:

(...) a dimensão da sociedade que inclui todo o conhecimento num sentido ampliado e todas as maneiras como este conhecimento é expresso. É uma dimensão dinâmica, criadora, ela mesma em processo, uma dimensão fundamental das sociedades contemporâneas (SANTOS, 1988, p. 50).

Geertz (1980) observa que sem o guia das imagens exteriorizadas, dos sentimentos falados no ritual, os mitos e a arte, não se teriam, de fato, como sentir. Tal como o próprio cérebro anterior desenvolvido, as idéias e as emoções são artefatos 
culturais do homem. Daí dizer que tanto as imagens quanto a escrita, enquanto heranças culturais, nos possibilitam uma aproximação com o tempo e espaço históricos, que protagonizam as experiências vividas ou imaginadas pelos seus atores sociais, expressas das mais diferentes maneiras, ao longo do tempo.

Conforme apontado e ainda segundo o posicionamento de outros autores, ao designar a cultura como um conjunto de significados construídos e partilhados pelos homens para explicar o mundo, Pesavento (2008, p. 15) a define ainda como

(...) uma forma de expressão e tradução da realidade, que se faz de forma simbólica, ou seja, admite-se que os sentidos conferidos às palavras, às coisas, às ações e aos atores sociais se apresentam de forma cifrada, portanto já um significado e uma apreciação valorativa.

Num breve panorama das correntes historiográficas sobre História Cultural vigentes no Brasil e no mundo que, a partir da década de 1980 passaram a ser questionadas e revisadas, a pesquisadora Sandra Pesavento (2008) introduz seu compêndio "História \& História Cultural" e apresenta argumentos importantes em torno das mudanças epistemológicas que perpassam esse novo olhar para a História. Conceitos como representação e Imaginário tão caros à historiografia cultural e que reorientam a postura do historiador, são fundamentados pela autora, que discute ainda questões ligadas à imagem enquanto valor documental, de época, não tomado no seu sentido mimético. Para Pesavento (2008, p.88):

O que importa é ver como os homens se representavam, a si próprios e ao mundo, e quais os valores e conceitos que experimentavam e que queriam passar, de maneira direta ou subliminar, com o que se atinge a dimensão simbólica da representação.

Isto pode ser mediado pela produção e recepção das imagens - sejam elas pictóricas, fotográficas, televisivas, entre outras - que estão amplamente imbricadas na vida social humana e das quais fazem parte os estudos da cultura visual, aqui entendida como um universo múltiplo de significados, cujos objetos "levam a refletir sobre as formas de pensamento da cultura na qual se produzem" (HERNÁNDEZ, 2000, p. 53).

\section{METODOLOGIA}

Ao considerar a abrangência desta proposta de pesquisa e os objetivos delineados para sua execução, a pesquisa foi submetida ao Comitê de Ética da Universidade. As observações e coleta de dados foram realizadas junto às turmas de $1^{\mathrm{a}} \mathrm{a}$ $5^{\text {a }}$ série do Ensino Fundamental bilíngüe da Escola Rui Barbosa de Joinville/SC, que conta com cerca de 120 alunos ouvintes e 58 alunos surdos, além dos professores de cada disciplina e intérpretes. Os encontros foram planejados e agendados com antecedência para não interferir nas atividades da escola.

\section{RESULTADOS E DISCUSSÃO}

De maneira breve, os principais aspectos levantados durante os processos de observação realizados em 2010 estão descritos no presente relato, bem como a descrição do primeiro jogo desenvolvido.

Foi constatado que, no intervalo, as crianças aproveitam o pátio do colégio para brincarem de pega-pega, corrida, pular corda e tênis de mesa. As brincadeiras são as mesmas, tanto para alunos surdos como para alunos ouvintes, porém, as crianças 
brincam separadamente. Percebeu-se que os alunos surdos se comunicam com outros colegas surdos de séries diversas, mas dificilmente se relacionam com colegas ouvintes da própria sala.

A $1^{\circ}$ série, neste caso, freqüentada apenas por alunos surdos, é onde acontece a apresentação e o primeiro contato formal em situação de ensino e aprendizagem, com a linguagem de Libras, visto que a maioria das crianças têm acesso ao idioma apenas quando entra na escola. A professora da turma é bilíngue e utiliza imagens para tornar possível um diálogo inicial com seus alunos e promover o ensino do alfabeto datilológico (alfabeto em Libras) e sinais básicos. Com esse método, atrai o olhar do aluno e concentra sua atenção. Os alunos são bastante curiosos e uma das atividades em que mais demonstram interesse é a de colorir. Apresentam dificuldade na apreensão dos temas mais abstratos, como, por exemplo, em matemática, quando se trata de quantidades e, em português, ao identificarem o nome dos objetos e animais, em decorrência de não conhecerem toda a gama de sinais em Libras.

Com a $5^{\circ}$ série, a aula transcorre de maneira um pouco diferente. Surdos e ouvintes compartilham o mesmo espaço, a mesma sala de aula e a professora vem acompanhada por uma intérprete. A docente explana o assunto e a intérprete traduz as informações para os alunos surdos, através da linguagem de Libras. Nos dias em que foram realizadas as observações, a professora não utilizou recurso visual como material de apoio. A divisão em sala é muito tangível: surdos ocupam uma metade da sala e alunos ouvintes, a outra, o que representa limitar a interação entre eles. Um pequeno número de alunos ouvintes conhece superficialmente a linguagem de Libras, e ainda alguns alunos surdos conseguem utilizar a escrita em português, possibilitando-lhes um diálogo, mesmo que superficial.

Realizou-se, além disso, uma pesquisa mais pontual com os alunos de $5^{\circ}$ série, no sentido de identificar os desenhos animados ou personagens com os quais têm maior proximidade, com o objetivo de verificar qual seria o enredo e os elementos ou pictogramas que mais atraem visualmente o público-alvo do jogo. Os desenhos com formas e histórias cujo conteúdo é mais complexo ou requer maior esforço auditivo foram os que menos agradaram, sendo que as opções ficaram concentradas naqueles que refletiam expressões faciais e corporais mais significativas, presentes na visualidade. Os desenhos, tanto caricaturados e estilizados quanto aqueles com personagens humanos, que conseguem ser compreendidos com mais facilidade e sem a utilização dos aspectos sonoros, foram os que mais se destacaram.

A partir dos resultados obtidos com as observações na Escola Rui Barbosa, verificou-se que a interação entre alunos surdos e ouvintes acontece de forma muito restrita, considerando que ambos não falam o mesmo idioma e isso acaba gerando limitações na comunicação, tanto entre os alunos, quanto da parte do professor com os alunos. Em algumas situações, os docentes têm dificuldades para compreenderem questionamentos dos alunos surdos, por não terem o domínio da linguagem de Libras, o que acaba interferindo também na apreensão da disciplina por parte do aluno.

Além dos aspectos das observações na escola, já mencionados, realizou-se, ainda, um encontro com duas professoras que atuam na Gerência da Educação de Joinville junto a programas de inclusão, bem como uma professora intérprete. Dentre as considerações levantadas, as profissionais confirmaram o que a literatura e as pesquisas realizadas para o desenvolvimento do presente projeto já haviam sinalizado: que é imprescindível a aquisição e o domínio da linguagem de Libras pelo surdo para a interação social, visando à construção da sua própria identidade. $\mathrm{O}$ indivíduo surdo possui seu campo visual muito aguçado, razão pela qual o ensino de Artes é a disciplina 
curricular preferida por eles, pois é o momento em que os surdos têm a oportunidade de trabalhar com atividades ligadas aos aspectos visuais, uma vez que apresentam maior facilidade para o desenho. É imprescindível, ainda, considerar que o jogo a ser projetado necessita proporcionar alguns requisitos, principalmente o de instigar a curiosidade, ou seja, conteúdos temáticos, suscitando vários resultados, possibilidades, desafios, autonomia, conhecimento de si próprio e do mundo. Temas ligados a atividades rotineiras e prazerosas como "ir à praia", visitar um zoológico, aspectos da cultura visual ou relacionado à escola. Quanto mais associados ao seu cotidiano, mais passíveis de despertarem o interesse das crianças, por isso a importância do emprego de elementos visuais como cores e texturas. Levantou-se, também, que os alunos sentem maior segurança ao desenvolverem suas atividades em grupo, considerando que ali há aspectos interativos e de grande significação para que haja a dialogicidade. Segundo as especialistas, dos professores que ministram aulas para as crianças surdas, muitos não conhecem Libras, principalmente por acomodação, o que gera falta de interesse e acomodação, já que nas salas dos surdos há sempre um intérprete.

Percebe-se, com isto, que o desenvolvimento de materiais lúdico-educativos que trabalhem a identidade, a visualidade, a autonomia, a criatividade e a atenção, tornam-se peças chave e instrumentos de grande valia, podendo ser utilizados pelo professor como ferramentas de comunicação, expressão, aprendizado e interação nas mais diversas séries e, ainda, pelos pais de alunos, que em sua grande maioria têm um diálogo restrito com os filhos, embora menos formal. Assim, com base na problematização levantada com as observações e relatos dos profissionais que trabalham com crianças surdas, foi desenvolvido em 2010 um Jogo de Tabuleiro cuja descrição segue:

O Jogo de Tabuleiro, ainda sem marca/nome definido, possui dois temas: "zoológico" e "praia", ou seja, o material tem duas faces, promovendo em um mesmo material, mais possibilidades de ação, visualização, manuseio, barateamento para aquisição e, ao mesmo tempo, aborda temas (animais, português, libras, matemática, artes, natureza em geral, entre outros) que podem ser explorados em diversas disciplinas curriculares antes e após a brincadeira. É formado por nove peças de $21 \mathrm{x} 21 \mathrm{~cm}$ de poliestireno, para facilitar a limpeza e aumentar a durabilidade, onde estão desenhadas partes do caminho a ser percorrido durante o jogo. Os jogadores podem distribuir as pequenas prachas na ordem que desejarem, pois todos os caminhos se encaixam, o que proporciona, já no início da atividade, uma discussão e possíveis acordos sobre como montar de forma estratégica o tabuleiro. Assim, cada vez que jogado, o caminho poderá ser diferentemente organizado, não deixando o jogo previsível e monótono. O número de jogadores pode ser de dois a seis, com idade mínima de 11 anos e, de preferência, para estimular a comunicação entre surdos e ouvintes, ser jogado por duplas mistas. No tema "zoológico" o objetivo do jogo é a alimentação para os animais. Estes estarão dispostos dentro de jaulas que não serão desenhadas, mas sim feitas em poliestireno e encaixadas no tabuleiro, para maior interação e atração visual. Cada um terá um personagem que poderá ser pintado antes de iniciar o jogo. Aspectos de intervenção como a pintura e identidade própria de cada personagem foram pensados, pois verificou-se que os surdos se interessam muito por atividades artísticas e manuais. No início no jogo, cada dupla ou equipe escolhe uma cor diferente e seis pacotinhos de comida, os quais deverão ser usados para alimentar os seis animaizinhos. Ganha quem alimentar o maior número de animais primeiro. Para obterem os alimentos, os jogadores deverão responder a pergunta que estiver correspondendo à casa em que se encontra no tabuleiro, avançando, recuando ou esperando, conforme a situação. Exemplificando: $\mathrm{O}$ personagem caiu em uma casa onde está escrito o número 3. Portanto, deverá responder 
à pergunta que está na carta marcada com o número 3. Respondendo corretamente, a equipe ganhará três pontos. Acumulando seis pontos, será possível "comprar" uma comidinha. Note-se que a quantidade de pontos ganhos corresponde ao número escrito na parte de trás da carta. Ou seja, se a equipe responder à pergunta com o número 1 , ganhará 1 ponto. Haverá uma roleta para definir o número de casas que o jogador deverá andar. Quem fará a pergunta será alguém de outra equipe. As perguntas estarão em libras, com desenhos e instruções e também em português. Deste modo, os ouvintes serão estimulados a prender a linguagem de libras, assim como os próprios surdos, que terão seu vocabulário ampliado, tanto na linguagem de libras quanto no português. As cartas serão encaixadas em uma base, para que as mãos não fiquem ocupadas no momento de executar as ações - gestos - com os sinais. Se a equipe errar a pergunta, não ganhará nem perderá pontos. Haverá mais de 15 personagens para serem escolhidos, pintados e montados pela equipe. A Figura 1 ilustra o jogo de tabuleiro desenvolvido:

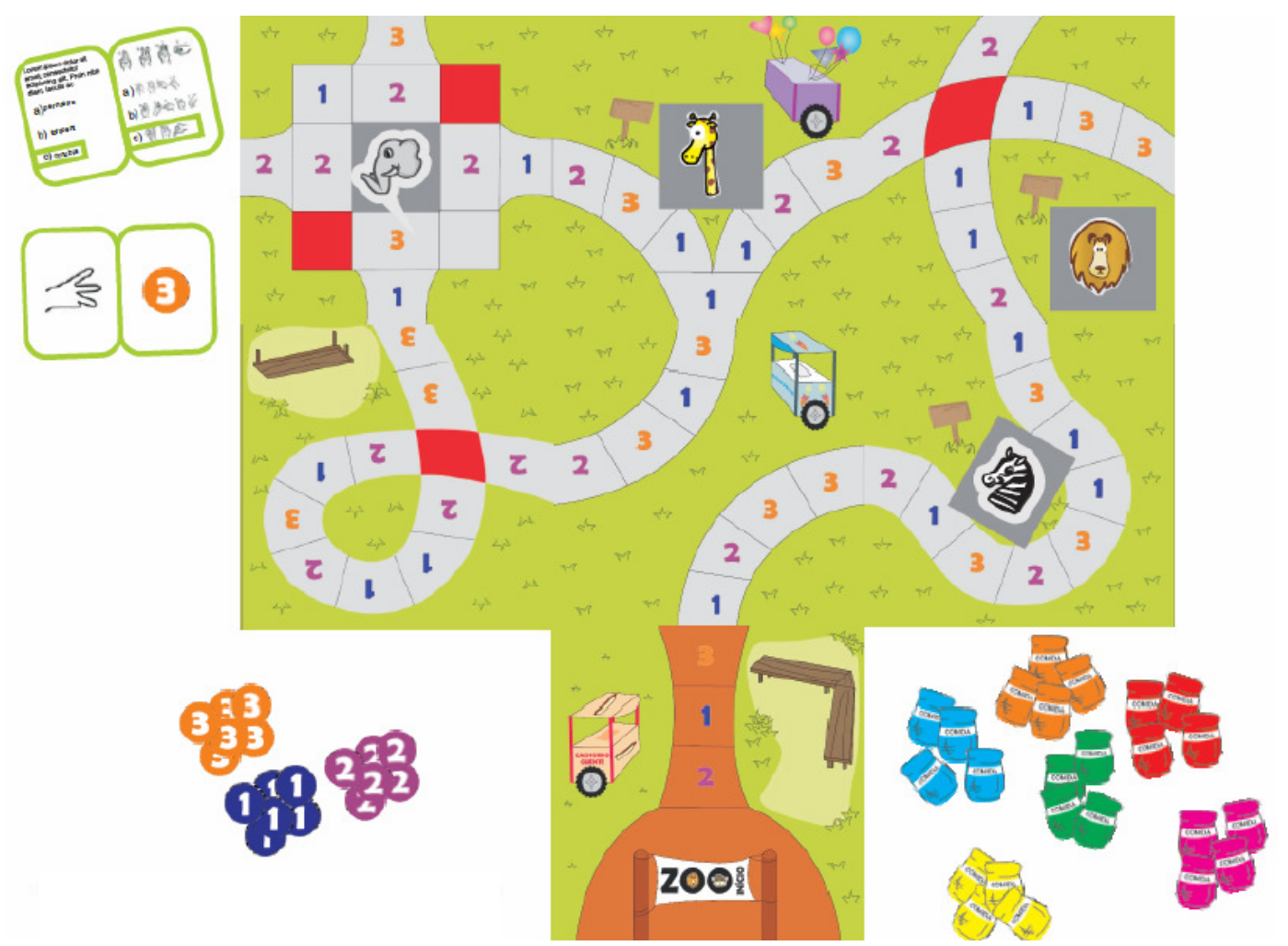

Figura 1 - Jogo de tabuleiro tema "zoológico".

O projeto encontra-se em fase de refinamento, ou seja, após a testagem do jogo com duas turmas de $5^{\circ}$ série - professores, intérprete e alunos foram levantados alguns aspectos que irão requerer novos olhares, distintas abordagens e outros posicionamentos. Esses momentos de testagem e experimentação podem ser entendidos, na área do design, como essenciais para o sucesso do produto. Ainda será necessário planejar para o produto, uma embalagem, visando facilitar seu manuseio e transporte.

A partir dos primeiros contatos da equipe pesquisadora com o tema deficiência auditiva e, após muitos estudos, processos de interação e discussões acerca das questões ligadas à comunicação e linguagem de Libras, a opção pela proposta de elaboração de um material lúdico pode se concretizar unindo experiências e demandas, tendo como 
possibilidade outras abordagens, no que diz respeito a novos materiais com a utilização de meios digitais, visando adequações mais rápidas e efetivas.

Salienta-se que a participação e o envolvimento de professores do Ensino Fundamental da Escola Rui Barbosa se deu de maneira colaborativa, sendo de grande valia cada um dos momentos vivenciados, onde cerca de seis professores e duas intérpretes que ministram conteúdos em salas de aula com crianças surdas e ouvintes, se propuseram a receber a equipe pesquisadora e ofereceram muitas sugestões e informações relevantes à pesquisa. Verificou-se, por meio de entrevistas e questionários com estes profissionais, a existência de uma significativa demanda no mercado pelo desenvolvimento de novos materiais lúdico-educativos para o ensino da linguagem de Libras. Isso, sem contar que, por muitas vezes, o próprio professor em sala precisa criar jogos ou materiais para ilustrar a aula. Mencionamos, ainda, a partir de levantamentos realizados, que aqueles materiais destinados aos surdos existentes no mercado são em número limitado, além de apresentarem baixa qualidade, serem pouco duráveis e apresentarem temas pouco atraentes aos alunos.

\section{CONCLUSÃO}

A despeito das experiências obtidas, muitos aspectos do jogo desenvolvido ainda estão por serem ajustados. Há algumas questões operacionais, que envolvem processos visuais e da linguagem de libras que necessitam ser solucionadas e, ainda, uma nova experiência junto aos grupos, como testagem e possibilidade de melhoria a partir da experimentação.

Embora se tenha constatado que a interação entre surdos e ouvintes ocorra de forma limitada pelo fato de não se comunicarem no mesmo idioma, o material de conteúdo lúdico acaba sendo um fomentador de outras formas de interação, o que vem a contribuir na compreensão, tanto da linguagem de sinais como da linguagem oral.

Trabalhar com uma proposta de material lúdico-educativo que busque desenvolver a identidade, a autonomia, a criatividade e a atenção, faz-se de grande valia, podendo ser utilizado pelo professor como ferramenta de comunicação, expressão, aprendizado e interação.

Ainda, há uma nova proposta onde se vislumbra a reedição do projeto com investigações que perpassam a materialidade do jogo que se encontra em fase de desenvolvimento, o que implicaria em estudos de linguagens virtuais e sua proposição como processo de interação entre crianças surdas e ouvintes.

\section{REFERENCIAS}

BROUGÈRE, Gilles. Brinquedos e companhia. São Paulo: Cortez; 2004.

CAPORALI, S.A; DIZEU, L.C.T. A língua de sinais constituindo o surdo como sujeito. Educ. Soc.,

Campinas, vol. 26, n. 91, p. 583-597, Maio/Ago. 2005. Disponível em $<$ http://www.cedes.unicamp.br> Acesso em jun. de 2010.

EDGAR, Andrew; SEDGWICK, Peter. Teoria cultural de A a Z: conceitos-chave para entender o mundo contemporâneo. São Paulo: Contexto, 2003.

FIDS - Fórum Internacional de Design Social. Conceito Geral. Disponível em: $<$ http://www.institutodamanha.com.br/forum/forum.htm>. Acesso em: 01 dez. 2009.

FRIEDMANN, Adriana. Brincar: crescer e aprender - o resgate do jogo infantil. São Paulo: Moderna, 1996.

GEERTZ, Clifford. Transição para a humanidade. In. ENGELS, Friedrich et al. O papel da cultura nas ciências sociais. Porto Alegre: Editorial Villa Martha Ltda, 1980. 
GESUELI, Z.M. Linguagem e identidade: a surdez em questão. Educ. Soc., Campinas, vol. 27, n. 94, p. 277-292, jan./abr. 2006. Disponível em <http://www.cedes.unicamp.br > Acesso em jun. de 2010.

HERNÁNDEZ, Fernando. Cultura visual, mudança educativa e projeto de trabalho. Porto Alegre: Artes Médicas Sul, 2000.

HUIZINGA, Johan. Homo ludens: o jogo como elemento da cultura. São Paulo: Perspectiva, 2008. LIMA, Mayumi. A cidade e a criança. São Paulo: Nobel, 1989.

LODI, Ana Claudia Balieiro. Plurilingüismo e surdez: uma leitura bakhtiniana da história da educação dos surdos. Educ. Pesqui. [online]. 2005, vol.31, n.3, pp. 409-424.

MARGOLIN, Victor; MARGOLIN, Sylvia. Um "Modelo Social" de Design: questões de prática e pesquisa. In: Revista Design em Foco, v.1, n.1, jul/dez 2004. Salvador: EDUNEB, 2004, p. 43-48.

PAULA, L.S.B de. Cultura escola, cultura surda e construção de identidades na escola. Educ. Soc., Campinas, vol. 26, n. 91, p. 565-582, Maio/Ago. 2005. Disponível em $<$ http://www.cedes.unicamp.br> Acesso em jun. de 2010.

PESAVENTO, Sandra Jatahy. História \& História Cultural. Belo Horizonte: Autêntica, 2008.

QUADROS, Ronice Muller de. Educação de surdos: a aquisição da linguagem. Porto Alegre: Artes Médicas, 1997.

QUEIROZ, Norma Lúcia Neris de, Et al. Brincadeira e desenvolvimento infantil: um olhar sociocultural construtivista. Paidéia, 2006, 16(34), 169-179.

SANTOS, José Luiz dos. O que é cultura. São Paulo: Editora Brasiliense, 1988.

SOUZA, R.G. Que palavra que te falta? Lingüística e educação: considerações epistemológicas a partir da surdez. São Paulo: Martins Fontes,1998.

VALSINER, J. (1988). Ontogeny of co-construcion of culture within socially organized environmental settings. In J. Valsiner (Ed.), Child development within culturally structured environments, 2, 283-297. New Jersey: Ablex Publishing Corporation. 